\title{
Maternal smoking during and after pregnancy and lung function in early adulthood: a prospective study
}

\author{
M R Hayatbakhsh, ${ }^{1}$ S Sadasivam, ${ }^{2}$ A A Mamun,, J M Najman, ${ }^{1}$ G M Williams, ${ }^{1}$ \\ M J O'Callaghan ${ }^{2}$
}

${ }^{1}$ School of Population Health, University of Queensland, Herston, Queensland, Australia; ${ }^{2}$ Mater Children's Hospital, South Brisbane, Queensland, Australia

Correspondence to: Dr M R Hayatbakhsh, University of Queensland, School of Population Health, Herston Road, Herston, Queensland 4006, Australia; m.hayatbakhsh@uq.edu.au

Received 8 March 2009 Accepted 1 June 2009 Published Online First 11 June 2009

\begin{abstract}
Background and aims: There is a paucity of evidence about whether exposure to antenatal smoking impacts on offspring's lung function in early adulthood. This study aimed to examine whether (1) in utero exposure to maternal smoking is related to poorer respiratory functioning in early adulthood; (2) the impact of prenatal smoking is independent of postnatal maternal smoking; and (3) the link between prenatal smoking and a young adult's lung function is explained by the child's birth weight, smoking or history of asthma.
\end{abstract}

Methods: Data were from a 21-year follow-up of mothers and their children recruited into the MaterUniversity of Queensland Study of Pregnancy, a longitudinal prebirth cohort. The study is based on 2409 young adults (1185 males and 1224 females) who had prospective data available on respiratory function at 21 years and maternal smoking during and after pregnancy. A Spirobank $\mathrm{G}$ spirometer system was used to measure forced vital capacity (FVC), forced expiratory volume in $1 \mathrm{~s}\left(\mathrm{FEV}_{1}\right)$ and forced expiratory flow between $25 \%$ and $75 \%$ of FVC ( $\left.\mathrm{FEF}_{25-75}\right)$.

Results: In utero exposure to maternal smoking was associated with a reduction in $\mathrm{FEV}_{1}$ and $\mathrm{FEF}_{25-75}$ in males (regression coefficient, $-0.16 ; 95 \% \mathrm{Cl},-0.30$ to -0.02 ), after accounting for maternal smoking after pregnancy. At least part of the effect of in utero smoking on young adults' lung function was explained by the child's birth weight and subsequent asthma.

Conclusions: Adverse effects of antenatal smoking on development of airway growth may persist into early adulthood. Gender differences noted in this longitudinal cohort need to be explored further.

It has long been established that maternal smoking during pregnancy has adverse consequences for both the mother and the child. ${ }^{2}$ Findings of studies which have examined the association between maternal smoking and offspring outcomes indicate that exposure to prenatal and/or postnatal smoking is linked to a reduced level of pulmonary function, ${ }^{3-6}$ an increased risk of asthma ${ }^{7-9}$ and respiratory infection. ${ }^{10}$ There is also evidence that exposure to prenatal smoking continues to impact on the offspring's respiratory function in later childhood. ${ }^{11-18}$ Part of the deficit in lung function seems to be related to asthma status in children. ${ }^{19}$ However, there is less known about whether the impact of maternal smoking during pregnancy continues into the offspring's early adulthood.

The effects of prenatal and postnatal tobacco smoke exposure can be difficult to distinguish since mothers who smoke during pregnancy invariably continue to do so thereafter. ${ }^{4}$ Large prospective birth cohort studies are needed to examine the effect of prenatal and postnatal smoking independently. Moreover, some studies suggest that in utero exposure to smoking increases the risk of negative pregnancy outcomes, such as low birth weight and premature birth, ${ }^{20}$ development of asthma in children ${ }^{9}$ and children smoking in early adolescence. ${ }^{21}$ Other research has found these factors to be associated with lung function in adulthood. ${ }^{22-24}$ Therefore, it seems plausible that these child factors may mediate the association between maternal smoking and the child's respiratory function.

Notwithstanding the strong evidence that in utero exposure to maternal tobacco smoking results in deficits of children's lung function measured soon after birth, there is uncertainty about whether this effect persists to early adulthood or whether there may be a period of catch-up growth. In addition to this, there is a need to examine potential mechanisms that may explain the association between prenatal smoking and a young adult's lung function. The present study aims to examine whether (1) in utero exposure to maternal smoking is related to lower respiratory functions in early adulthood; (2) the impact of prenatal smoking is independent of postnatal maternal smoking; and (3) the link between prenatal smoking and a young adult's lung function is explained by the child's birth weight, smoking or history of asthma. As gender has been proposed to influence the impact of maternal smoking on children's lung function, ${ }^{513}$ our analyses are conducted separately for males and females.

\section{METHODS \\ Subjects}

Data for this report are derived from the MaterUniversity of Queensland Study of Pregnancy (MUSP) and its outcomes. Details of this project have been previously reported. ${ }^{25} 26$ Briefly, commencing in 1981, 8556 consecutive women in early pregnancy were invited to participate in the study. Some 8458 agreed to participate and 7223 gave birth to a live singleton baby at the study hospital. Mothers and children were subsequently followedup at 3-5 days, 6 months, and 5, 14 and 21 years after the child's birth. At the 21-year follow-up, 5185 young adults (of the cohort of singleton babies) whose mothers had previously (at the 14year follow-up) agreed to be contacted again were sent a questionnaire. Almost 3700 completed the questionnaire, of whom a subsample of 2612 
Table 1 Loss to follow-up at 21 years according to mother and child characteristics

\begin{tabular}{|c|c|c|c|}
\hline & \multirow[b]{3}{*}{ No } & \multicolumn{2}{|c|}{ Remaining at the 21-year follow-u } \\
\hline & & \multicolumn{2}{|l|}{ No (row \%) } \\
\hline & & Self-report & $\begin{array}{l}\text { Physical } \\
\text { assessment }\end{array}$ \\
\hline \multicolumn{4}{|l|}{ Children's gender } \\
\hline Male & 3757 & $1784(47.5)$ & $1293(34.4)$ \\
\hline Female & 3465 & $1964(56.7)^{*}$ & $1319(38.1)^{* *}$ \\
\hline \multicolumn{4}{|l|}{ Mother's age at pregnancy } \\
\hline$<20$ years & 1181 & $491(41.6)$ & $358(30.3)$ \\
\hline 20-34 years & 5722 & $3083(53.9)$ & $2128(37.2)$ \\
\hline$\geqslant 35$ years & 319 & $174(54.6)^{*}$ & $126(39.5)^{*}$ \\
\hline \multicolumn{4}{|c|}{ Mother's education at pregnancy } \\
\hline Incomplete high school & 1305 & $742(59.1)$ & $514(36.2)$ \\
\hline Complete high school & 4608 & $2390(51.9)$ & $1665(36.1)$ \\
\hline Tertiary education & 1256 & $591(45.3)^{*}$ & $416(40.9)^{*}$ \\
\hline \multicolumn{4}{|c|}{ Maternal smoking during pregnancy } \\
\hline No & 4394 & $2442(55.6)$ & $1665(37.9)$ \\
\hline Yes & 2757 & $1269(46.0)^{*}$ & $922(33.4)^{*}$ \\
\hline
\end{tabular}

young adults (average 21 years of age) were administered a physical assessment including lung function tests. Persons living outside Brisbane or who were unable to make an appointment for a face to face interview completed a mailed questionnaire and did not undergo the physical assessment. Informed consent was appropriately obtained from all participants.

\section{Measurements \\ Lung function tests}

Pulmonary function testing was performed at the 21-year follow-up using a Spirobank G spirometer system attached to a laptop computer. Qualified and trained interviewers familiar with the instrument were employed to perform spirometric tests, in accordance with American Thoracic Society (ATS) guidelines. ${ }^{27} \mathrm{~A}$ minimum of three trials and a maximum of five were attempted. If testing was unsatisfactory for any reason, the reason(s) were noted on the record sheets. For the purpose of this study forced vital capacity (FVC), forced expiratory volume in $1 \mathrm{~s}\left(\mathrm{FEV}_{1}\right)$ and forced expiratory flow, midexpiratory phase $\left(\mathrm{FEF}_{25-75}\right)$, were considered as outcomes of interest.

\section{Maternal smoking}

At each follow-up of the MUSP the mothers were asked to indicate the number of cigarettes they smoked per day during the last week. Options for this question were structured as none, 1-9, 10-19, 20-29, 30-49, and 50 or more cigarettes per day. Using the mothers' responses at each phase, they were divided into two categories: non-smoker and smoker. For the purpose of this study self-reported maternal smoking is used at first clinic visit (average 18 weeks pregnancy), and when the child was 6 months, 5 and 14 years. Using information about maternal smoking at the first clinic visit and at child age 6 months, 5 and 14 years, we created a composite variable that included three categories: did not smoke during or after pregnancy, smoked at other times but not during pregnancy, and smoked during pregnancy regardless of other times.

\section{Other variables}

The age of the mothers was assessed at entry to the study (mothers were divided into three categories, $<20$ years, 20-34 years and $\geqslant 35$ years. The level of a mother's education was assessed at entry to the study (they were divided into three groups: incomplete high school, completed high school and tertiary education). The child's birth weight was measured in grams at the hospital (children were divided into three categories, $<2500$ g, 2500-3999 g and $\geqslant 4000$ g). The extent of smoking by children at 14 years was assessed via self-report. Based on their responses we divided participants into two categories: non-smokers and smokers. A self-reported history of asthma was recorded at the 21-year follow-up. The participants were also asked about taking asthma medication in the last 2 weeks or having ever been admitted to hospital because of an asthma attack.

\section{Statistics}

For this analysis, we included 2409 young adults who underwent spirometry at 21 years and for whom data were available about maternal smoking during and after pregnancy. The outcome variables were: FVC, $\mathrm{FEV}_{1}$ and $\mathrm{FEF}_{25-75}$. Exposure variables were maternal smoking during pregnancy and at child age 6 months, 5 and 14 years. A child's birth weight, a child smoking at 14 years and history of childhood asthma were associated with both maternal smoking during pregnancy and a young adult's respiratory function and, therefore, were considered as potential mediating factors between prenatal smoking and a child's lung function at 21 years. The analyses were conducted separately for males and females.

We primarily used $\chi^{2}$ tests to examine the association between baseline characteristics of the participants and loss to follow-up at 21 years. Univariate and multivariate linear regression models were used to predict the three spirometry tests according to maternal smoking at first clinic visit, 6 months, 5 years and 14 years. Subsequently, we used univariate linear regression to examine the association between a child's respiratory function and exposure to maternal smoking during and after pregnancy. The analyses involved both the exact value and the z-score (adjusted internally for a participant's age and height within the cohort measured at the 21-year

Table 2 Association between maternal smoking during and after pregnancy and children's lung function at 21 years (males only)

\begin{tabular}{|c|c|c|c|c|c|c|}
\hline \multirow[b]{3}{*}{ Maternal smoking } & \multicolumn{6}{|c|}{ Lung function tests } \\
\hline & \multicolumn{2}{|l|}{ FVC (litre) } & \multicolumn{2}{|l|}{ FEV $_{1}$ (litre) } & \multicolumn{2}{|l|}{ FEF $_{25-75}$ (litre/s) } \\
\hline & Univariate & Multivariate & Univariate & Multivariate & Univariate & Multivariate \\
\hline First clinic visit & $-0.003(0.05)$ & $-0.155(0.09)$ & $-0.062(0.04)$ & $-0.153(0.08)^{* *}$ & $-0.188(0.07)^{*}$ & $-0.262(0.13)^{* *}$ \\
\hline 6 months & $0.026(0.05)$ & $0.157(0.10)$ & $-0.029(0.04)$ & $0.063(0.08)$ & $-0.144(0.07)^{* *}$ & $-0.071(0.13)$ \\
\hline 5 years & $0.011(0.05)$ & $0.005(0.09)$ & $-0.009(0.04)$ & $0.078(0.07)$ & $-0.042(0.07)$ & $0.269(0.12)$ \\
\hline 14 years & $0.008(0.05)$ & $-0.022(0.08)$ & $-0.043(0.04)$ & $-0.054(0.06)$ & $-0.144(0.07)^{* *}$ & $-0.125(0.11)$ \\
\hline
\end{tabular}

Values are regression coefficients (SE).

FVC, forced vital capacity; $\mathrm{FEF}_{25-75}$, forced expiratory flow between $25 \%$ and $75 \%$; $\mathrm{FEV}_{1}$, forced expiratory volume in $1 \mathrm{~s}$

${ }^{*} \mathrm{p}<0.01 ;{ }^{*} \mathrm{p}<0.05$ 
Table 3 Association between maternal smoking during and after pregnancy and children's lung function at 21 years (females only)

\begin{tabular}{|c|c|c|c|c|c|c|}
\hline \multirow[b]{3}{*}{ Maternal smoking } & \multicolumn{6}{|c|}{ Lung function tests } \\
\hline & \multicolumn{2}{|l|}{ FVC (litre) } & \multicolumn{2}{|l|}{$\mathrm{FEV}_{1}$ (litre) } & \multicolumn{2}{|l|}{ FEF $_{25-75}$ (litre/s) } \\
\hline & Univariate & Multivariate & Univariate & Multivariate & Univariate & Multivariate \\
\hline 6 months & $-0.002(0.03)$ & $0.028(0.06)$ & $-0.007(0.03)$ & $0.042(0.05)$ & $-0.057(0.05)$ & $0.016(0.10)$ \\
\hline 5 years & $-0.023(0.04)$ & $-0.026(0.06)$ & $-0.022(0.03)$ & $-0.004(0.05)$ & $-0.029(0.05)$ & $0.058(0.10)$ \\
\hline 14 years & $0.001(0.04)$ & $0.022(0.06)$ & $-0.023(0.03)$ & $-0.021(0.05)$ & $-0.066(0.05)$ & $-0.077(0.09)$ \\
\hline
\end{tabular}

Values are regression coefficients (SE).

FVC, forced vital capacity; $\mathrm{FEF}_{25-75}$, forced expiratory flow between $25 \%$ and $75 \%$; $\mathrm{FEV}_{1}$, forced expiratory volume in $1 \mathrm{~s}$.

follow-up) of the three spirometry tests. Children not exposed to maternal smoking during and after pregnancy were considered the referent group. We then used three separate multivariate regression models to adjust the association between maternal smoking and a young adult's lung function for the mediating variables (a child's birth weight, a child smoking and history of asthma) existing in the data set. The results reported are the estimated differences in lung function (in litres) for exposed children relative to unexposed children. The associations were considered statistically significant if $\mathrm{p}<0.05$. All analyses were conducted using Stata v.10 and SPSS v.15.

\section{RESULTS}

\section{Descriptive findings}

A total of 2612 young adults (49.2\% males and $50.8 \%$ females) underwent lung function tests at the 21-year follow-up. Nonparticipation at the 21-year follow-up was significantly related to the child gender, mother's socio-demographic background when the child was born, and smoking during pregnancy (see table 1). Participants had a mean age of 20.4 years (range between 18.2 and 23.1 years). The means (SD) of the lung function tests for males were FVC 5.39 (0.81) litres, $\mathrm{FEV}_{1} 4.55$ (0.66) litres and $\mathrm{FEF}_{25-75} 4.78$ (1.13) litres/s. Spirometry tests for females were FVC 3.84 (0.58) litres, $\mathrm{FEV}_{1} 3.34$ (0.45) litres and $\mathrm{FEF}_{25-75} 3.77$ (0.86) litres/s. The mean differences between males and females were statistically significant $(p<0.001)$. Of participants who were administered spirometry tests, 2409 had data available on maternal smoking during and after pregnancy. Some $38.5 \%$ of mothers reported smoking at their first clinic visit, $43.4 \%$ smoked at child age 6 months, 36.8\% smoked at child age 5 years and $31.4 \%$ smoked at child age 14 years. Overall, $49.1 \%$ of mothers reported they did not smoke at all. Another $12.6 \%$ reported smoking after the birth but not in pregnancy, and $38.3 \%$ of mother smoked during pregnancy regardless of whether they smoked postnatally (only 18 women reported smoking during but not after pregnancy).

\section{Maternal smoking and young adult lung function}

Tables 2 and 3 show findings of the association between maternal smoking at four phases of the study and measures of young adults' lung function at 21 years, for males and females, respectively. For males only, maternal smoking during the pregnancy or when the child was aged 6 months and 14 years was associated with poorer respiratory function tests at 21 years. There was a statistically significant reduction in $\mathrm{FEF}_{25-75}$ and $\mathrm{FEV}_{1}$ of the children whose mothers had smoked in pregnancy. In addition, in mothers who smoked cigarettes when their child was aged 6 months or 14 years their children were more likely to have impaired $\mathrm{FEF}_{25-75}$ at 21 years. However, multivariate regression analyses showed a significant association between only maternal smoking during pregnancy and young adults' $\mathrm{FEF}_{25-75}$. Unlike males, maternal smoking during or after pregnancy was not associated with reduced respiratory function for females.

Using the three-category composite variable, we examined the relationship between exposure to passive smoking (during and after pregnancy) and respiratory function at child age 21 (table 4). Male participants who have been exposed to maternal smoking during pregnancy had a statistically significant reduction in $\mathrm{FEF}_{25-75}$ and $\mathrm{FEV}_{1}$ compared with those of nonsmoking mothers or those who were exposed to maternal smoking after, not during, pregnancy. The respiratory function tests in children of mothers who smoked at 6 months, 5 years or 14 years (but not during pregnancy) were not statistically different from those of non-smoking mothers. For females, none of the measures of respiratory function at 21 years was related to maternal smoking during or after pregnancy.

Table 4 Association between exposure to maternal smoking during and after pregnancy and children' lung function at 21 years by gender

\begin{tabular}{|c|c|c|c|c|c|c|}
\hline \multirow[b]{2}{*}{ Lung function tests } & \multicolumn{3}{|c|}{ Males $(n=1185)$} & \multicolumn{3}{|c|}{ Females $(n=1224)$} \\
\hline & $\begin{array}{l}\text { Never } \\
\text { smoked }\end{array}$ & Smoked after & $\begin{array}{l}\text { Smoked during } \\
\pm \text { after }\end{array}$ & $\begin{array}{l}\text { Never } \\
\text { smoked }\end{array}$ & Smoked after & $\begin{array}{l}\text { Smoked during } \\
\pm \text { after }\end{array}$ \\
\hline FVC (litre) & Ref & $0.06(0.08)$ & $0.02(0.05)$ & Ref & $0.07(0.05)$ & $0.01(0.04)$ \\
\hline z-score & Ref & $-0.05(0.09)$ & $0.12(0.06)$ & Ref & $0.14(0.08)$ & $0.05(0.06)$ \\
\hline $\mathrm{FEV}_{1}$ (litre) & Ref & $0.06(0.06)$ & $-0.04(0.04)$ & Ref & $0.06(0.04)$ & $-0.01(0.03)$ \\
\hline z-score & Ref & $0.11(0.09)$ & $-0.17(0.06)^{*}$ & Ref & $-0.05(0.09)$ & $-0.05(0.06)$ \\
\hline $\mathrm{FEF}_{25-75}$ (litre/s) & Ref & $0.10(0.11)$ & $-0.16(0.07)^{* *}$ & Ref & $0.01(0.08)$ & $-0.06(0.05)$ \\
\hline z-score & Ref & $0.06(0.09)$ & $-0.10(0.06)$ & Ref & $0.009(0.08)$ & $-0.03(0.06)$ \\
\hline
\end{tabular}

The reference group (Ref) is children whose mothers never smoked. Values are regression coefficients (SE).

${ }^{*} \mathrm{p}<0.01 ;{ }^{* *} \mathrm{p}<0.05$.

FVC, forced vital capacity; $\mathrm{FEF}_{25-75}$, forced expiratory flow between $25 \%$ and $75 \%$; $\mathrm{FEV}_{1}$, forced expiratory volume in $1 \mathrm{~s}$ 
Table 5 Association between exposure to maternal smoking during and after pregnancy and children's lung function at 21 years in males adjusted for mediating factors

\begin{tabular}{|c|c|c|c|}
\hline Maternal smoking during and after pregnancy & FVC (litre) & FEV $_{1}$ (litre) & FEF $_{25-75}$ (litre/s) \\
\hline \multicolumn{4}{|l|}{ Adjusted for birth weight } \\
\hline Never smoked & Ref & Ref & Ref \\
\hline Smoked after pregnancy & $0.04(0.08)$ & $0.06(0.06)$ & $0.11(0.10)$ \\
\hline Smoked during \pm after pregnancy & $0.07(0.05)$ & $0.001(0.04)$ & $-0.11(0.07)$ \\
\hline \multicolumn{4}{|l|}{ Adjusted for child smoking at 14 years } \\
\hline Never smoked & Ref & Ref & Ref \\
\hline Smoked after pregnancy & $0.07(0.08)$ & $0.07(0.06)$ & $0.12(0.11)$ \\
\hline Smoked during \pm after pregnancy & $0.02(0.05)$ & $-0.04(0.04)$ & $-0.15(0.07)^{*}$ \\
\hline \multicolumn{4}{|l|}{ Adjusted for history of asthma assessed at 21 years } \\
\hline Never smoked & Ref & Ref & Ref \\
\hline Smoked after pregnancy & $0.06(0.08)$ & $0.07(0.06)$ & $0.12(0.10)$ \\
\hline Smoked during \pm after pregnancy & $0.03(0.05)$ & $-0.02(0.04)$ & $-0.11(0.07)$ \\
\hline
\end{tabular}

The reference group (Ref) is children whose mothers never smoked. Values are regression coefficients (SE).

${ }^{*} \mathrm{p}<0.05$.

FVC, forced vital capacity; $\mathrm{FEF}_{25-75}$, forced expiratory flow between $25 \%$ and $75 \%$; $\mathrm{FEV}_{1}$, forced expiratory volume in $1 \mathrm{~s}$.

\section{Impact of mediating factors}

Children whose mothers smoked cigarettes in pregnancy were more likely to have had a low birth weight $(<2500 \mathrm{~g})$ relative to non-smoking mothers $(5.9 \%$ vs $3.2 \%)(p<0.001)$, to report tobacco smoking at 14 years and to report a history of asthma at 21 years compared with other children. These three variables were considered potential mediating factors for the impact of maternal smoking on a child's lung function. Table 5 shows the association between maternal smoking and respiratory function at 21 years (males only) controlled for the child's birth weight, child smoking assessed at 14 years and history of asthma assessed at 21 years. The three variables were controlled in separate regression models. Adjustment for the child's birth weight led the association between maternal smoking during pregnancy and $\mathrm{FEF}_{25-75}$ to become statistically non-significant. Inclusion of child smoking at 14 years in the regression model did not materially change the association between maternal smoking during pregnancy and the child's respiratory function at 21 years. When the association was corrected for asthma, there was no longer a statistically significant association between maternal smoking during pregnancy and a child's $\mathrm{FEF}_{25-75}$ or $\mathrm{FEV}_{1}$ at 21 years.

\section{Sensitivity analysis}

In our cohort there were only 18 women who quit smoking after pregnancy. Due to this very small number, we were not able to examine the impact of gestational smoking on lung function independent of smoking at other times. However, in a complementary analysis, we excluded those 18 people and repeated the analysis. The findings were not different from those presented in table 4. In a study of 12743 children, Taylor and Wadsworth ${ }^{10}$ found that maternal smoking during pregnancy and continuous smoking during and after pregnancy had a comparable impact on children's lower respiratory tract in the first 5 years. In our cohort there were 75 women who smoked cigarettes before pregnancy but became non-smokers after pregnancy. Our additional analysis showed that maternal ex-smoking (before pregnancy but not other times) had no statistically significant impact on young adults' lung function. In addition, at the 21-year follow-up, 251 participants reported previous admission to hospital because of asthma. Consistent with the data presented in table 5 the association of maternal smoking during pregnancy and lung function when this group was excluded from the analysis was not statistically significant.

\section{DISCUSSION}

This is the first study to examine the effects of maternal smoking during pregnancy on offspring's lung function in early adulthood. The results of this study show that in utero exposure to maternal smoking is associated with a modest reduction in small airway flow rates in males, though not females, after accounting for maternal smoking after pregnancy. Although postnatal smoking was also associated with lower small airway flows, the deficits were substantially reduced when adjusted for in utero exposure. Indeed exposure to maternal smoking between 6 months and 14 years, independent of prenatal smoking, did not predict lower lung function at 21 years. The finding of this study did not show evidence that FVC is adversely affected by either in utero or postnatal exposure to maternal smoking. This discordance between the FVC and the $\mathrm{FEV}_{1}$ and $\mathrm{FEF}_{25-75}$ raises the possibility of catch-up growth occurring in terms of the vital capacity. As anticipated, the data also suggested that at least part of the effect of in utero smoking is explained by a child's birth weight and subsequent asthma.

A considerable body of evidence supports the plausibility that in utero exposure can produce persistent deficits in childhood lung function. ${ }^{511} 1315172829$ Recent studies of lung function in neonates and infants of mothers who smoked during pregnancy have shown that in utero exposure is associated with reduced lung function in the perinatal period. ${ }^{15}{ }^{28}$ The deficits observed at birth appear to persist into childhood and adolescence, especially in measures associated with small airway flow rates. ${ }^{11} 1329$ Relative to prenatal exposure to maternal smoking, there is no clear evidence that postnatal exposure to maternal smoking has an independent effect on the child's lung function. Our data support the previous findings that exposure to prenatal smoking is associated with lower lung function in childhood and adolescence. However, it does not suggest that independent exposure to postnatal maternal smoking impacts lung function in early adulthood.

Our findings are in agreement with previous research which has found a non-significant or weaker association for maternal smoking in girls. ${ }^{5}{ }^{13}$ This effect appears to persist, though it abates, into adulthood, as shown by the respiratory function at 21 years for the male offspring. The present study indicates that 
the modest impact of smoking in pregnancy on adulthood lung function is limited to male offspring. The reasons for this gender difference are still not fully understood. One possibility is that the growth of lungs might have independent pathways, which respond differently to the effects of smoking. As an addition to the current literature, this study suggests that child birth weight mediates at least part of the association between prenatal smoking and lung function. Previous research indicated that in utero exposure to smoking has a stronger effect on lung function in children with asthma. ${ }^{19}$ Our data did not find evidence of an effect of exposure to in utero smoking on lung function amongst individuals without a history of asthma.

The present study relied on self-reports of maternal smoking in pregnancy and during child development, adolescent smoking and young adult history of asthma. There is a possibility that mothers under-report their smoking in pregnancy. Such potential misclassification might have led to underestimation of the impact of maternal smoking on the child's lung function. A possibility of under-reporting of smoking by adolescents at 14 years may have led to a non-significant effect of this potential mediating factor in the association of maternal smoking and young adults' lung function. Additionally, self-reported history of asthma is subject to non-differential misclassification that could have biased the association towards the null value. A second limitation is that in the MUSP we did not measure paternal smoking during child development. While this may affect the child respiratory function due to postnatal exposure to smoking, a review of studies that compared the effects of maternal and paternal smoking reports the effect of maternal smoking to be greater than that of paternal smoking (often reported to be zero). ${ }^{5}$

Another limitation is the sizeable reduction in the sample between the assessment of maternal smoking at first antennal visit and the 21-year follow-up. Of the 5950 subjects for whom we collected information related to maternal smoking between pregnancy and 14-year follow-up, only $40.5 \%$ underwent spirometry tests as young adults. Over 21 years follow-up, for mothers who smoked at any phases of the study their children were more likely to drop out of the study by the 21-year followup $(p<0.01)$. Drop-out in the study may influence our results in two different ways. If the association between maternal smoking and young adult lung function in those lost to follow-up was higher than in the study group, our findings would underestimate the true association. There is a threat to the validity of our findings if the association we have observed is not evident or is in the opposite direction among those lost to follow-up. Given the likely causal pathways and the positive association reported by other authors, overestimating the relationship is unlikely.

The exposure to in utero smoking, regardless of maternal smoking postnatally, has a significant, though modest, effect on lung function in the offspring, specifically males. This association is mediated by the child's birth weight and history of asthma. The data presented in our study suggest clinical and public health implications. Reducing the burden of chronic respiratory diseases associated with tobacco smoke may also require the reduction of smoking among women during their childbearing years, and in particular during pregnancy.

Acknowledgements: We thank all participants in the study, the MUSP data collection team and Greg Shuttlewood, and the University of Queensland who has helped to manage the data for the MUSP.

Competing interests: None.
Ethics approval: Ethics approval was obtained from the University of Queensland \& Mater Hospital.

Provenance and peer review: Not commissioned; externally peer reviewed.

\section{REFERENCES}

1. Patrick PL, Bauman A. How well does epidemiological evidence hold for the relationship between smoking and adverse obstetric outcomes in New South Wales? Aust NZ J Obstet Gynaecol 1997;37:168-73.

2. Bai J, Wong FW, Gyaneshwar R, et al. Profile of maternal smokers and their pregnancy outcomes in south western Sydney. J Obstet Gynaecol Res 2000;26:127-32.

3. Stocks J, Dezateux C. The effect of parental smoking on lung function and development during infancy. Respirology 2003;8:266-85.

4. Strachan DP, Cook DG. Health effects of passive smoking. 1. Parental smoking and lower respiratory illness in infancy and early childhood. Thorax 1997;52:905-14.

5. Cook DG, Strachan DP, Carey IM. Health effects of passive smoking. 9. Parental smoking and spirometric indices in children. Thorax 1998;53:884-93.

6. Cook DG, Strachan DP. Health effects of passive smoking. 10. Summary of effects of parental smoking on the respiratory health of children and implications for research. Thorax 1999;54:357-66

7. Milner AD, Rao $\mathrm{H}$, Greenough $\mathrm{A}$. The effects of antenatal smoking on lung function and respiratory symptoms in infants and children. Early Hum Dev 2007;83:707-11.

8. Pattenden S, Antova T, Neuberger M, et al. Parental smoking and children's respiratory health: independent effects of prenatal and postnatal exposure. Tob Control 2006;15:294-301.

9. Gilliland FD, Li YF, Peters JM. Effects of maternal smoking during pregnancy and environmental tobacco smoke on asthma and wheezing in children. Am J Respir Crit Care Med 2001;163:429-36.

10. Taylor B, Wadsworth J. Maternal smoking during pregnancy and lower respiratory tract illness in early life. Arch Dis Child 1987:62:786-91.

11. Cunningham J, Dockery DW, Speizer FE. Maternal smoking during pregnancy as a predictor of lung function in children. Am J Epidemiol 1994;139:1139-52.

12. Cunningham J, O'Connor GT, Dockery DW, et al. Environmental tobacco smoke, wheezing, and asthma in children in 24 communities. Am J Respir Crit Care Med 1996;153:218-24

13. Cunningham J, Dockery DW, Gold DR, et al. Racial differences in the association between maternal smoking during pregnancy and lung function in children. Am J Respir Crit Care Med 1995;152:565-9.

14. Stick SM, Burton PR, Gurrin L, et al. Effects of maternal smoking during pregnancy and a family history of asthma on respiratory function in newborn infants. Lancet 1996;348:1060-4.

15. Tager IB, Ngo L, Hanrahan JP. Maternal smoking during pregnancy. Effects on lung function during the first 18 months of life. Am J Respir Crit Care Med 1995;152:977-83.

16. Tager IB, Segal MR, Munoz A, et al. The effect of maternal cigarette smoking on the pulmonary function of children and adolescents. Analyses of data from two populations. Am Rev Respir Dis 1987;136:1366-70.

17. Wang $\mathbf{X}$, Wypii D, Gold DR, et al. A longitudinal study of the effects of parental smoking on pulmonary function in children 6-18 years. Am J Respir Crit Care Med 1994;149:1420-5.

18. Moshammer H, Hoek G, Luttmann-Gibson $\mathrm{H}$, et al. Parental smoking and lung function in children: an international study. Am J Respir Crit Care Med 2006;173:1255-63.

19. Li YF, Gilliland FD, Berhane K, et al. Effects of in utero and environmental tobacco smoke exposure on lung function in boys and girls with and without asthma. Am J Respir Crit Care Med 2000;162:2097-104.

20. Secker-Walker RH, Vacek PM. Relationships between cigarette smoking during pregnancy, gestational age, maternal weight gain, and infant birthweight. Addict Behav 2003:28:55-66.

21. O'Callaghan FV, O'Callaghan M, Najman JM, et al. Prediction of adolescent smoking from family and social risk factors at 5 years, and maternal smoking in pregnancy and at 5 and 14 years. Addiction 2006:101:282-90.

22. Willemse BWM, Postma DS, Timens W, et al. The impact of smoking cessation on respiratory symptoms, lung function, airway hyperresponsiveness and inflammation. Eur Respir J 2004;23:464-76.

23. Edwards CA, Osman LM, Godden DJ, et al. Relationship between birth weight and adult lung function: controlling for maternal factors. Thorax 2003;58:1061-5.

24. Tennant PW, Gibson GJ, Pearce MS. Lifecourse predictors of adult respiratory function: results from the Newcastle Thousand Families Study. Thorax 2008;63:823-30.

25. Hayatbakhsh MR, Najman JM, Jamrozik K et al. Cannabis and anxiety and depression in young adults: a large prospective study. J Am Acad Child Adolesc Psychiatry 2007:46:408-17.

26. Najman JM, Bor W, O'Callaghan M, et al. Cohort profile: the Mater-University of Queensland Study of Pregnancy (MUSP). Int J Epidemiol 2005;34:992-7.

27. American Thoracic Society. Standardization of spirometry, 1994 update. American Thoracic Society. Am J Respir Crit Care Med 1995;152:1107-36.

28. Hanrahan JP, Tager IB, Segal MR, et al. The effect of maternal smoking during pregnancy on early infant lung function. Am Rev Respir Dis 1992;145:1129-35.

29. Jedrychowski W, Flak E, Mroz E. Cigarette smoking by mothers during pregnancy and pulmonary function of their school age children. Pneumonol Alergol Pol 1997;65:605-10. 